was wonderful, dear. How was it for you?"

RUTH CLAYTON Reader Emeritus, ICAPB,

Division of Biological Sciences, University of Edinburgh,

Crew Annexe, King's Buildings,

West Mains Road,

Edinburgh EH9 37N

\section{Health Care for an Aging Population}

\section{Edited by Chris Hackler, New York, State University of New York Press, 1994, 232 pages, US\$18.95.}

Allocation of health care resources and access to them is a widely debated issue throughout the world. This book is a collection of essays by multiple authors in response to Daniel Callahan's book Setting Limits: Medical Goals in an Aging Society. Callahan proposed withholding lifesaving treatment from the very elderly as a form of rationing. The discussion relates to the American health care system although the broader issues are applicable elsewhere, with future resources being more limited and with ever-expanding numbers of elderly patients requiring treatment.

There is consensus amongst the authors that the US health care system needs reform, with universal right of access for all to basic health care but that non-basic care is not a universal right. The specific health needs of the elderly must be met ahead of high-technology acute care, with special reference to long-term and home care with palliation and relief of suffering. The positive image of aging needs to be promoted, stressing the large contributions that elderly people have to make to society, in the face of the current climate of intergenerational conflict that is so pervasive.

Rationing of health care will become imperative as there is increasing demand, but in an era of cost containment resources are finite and therefore will be limited. The methods by which rationing can be applied and savings achieved are addressed in this book, with a variety of proposals. Rationing can be resource-based, applied by government, legislators or administrators, or it can be patientcentred, performed at the site of delivery by physicians. Callahan's proposals are discussed in detail in chapter 6 where the scarcity of resources is stressed and the importance of allocating such resources effectively and with maximal medical benefit is seen as paramount.

Some authors think age-based rationing is ethically immoral, taking care away from those most deserving and most in need. Callahan and others have agreed that it is a form of discrimination against the elderly, but contend that the alternatives may be even worse, limiting health care to younger individuals who have not yet achieved their full potential in life. He feels that the elderly themselves would see the sense of his argument if the issues were properly addressed. Stysma thinks that Callahan has used age wrongly, when quality-of-life considerations actually underlie his argument. If a natural lifespan is adopted for rationing, then it ignores the significant quality of life possible for the healthy elderly person with an eminently treatable infection.

Perhaps the most important issue to be discussed in this book is the nature of rationing. In the present climate, rationing does occur in an implicit manner which is not perceived as iniquitous, such as lack of provision of nursing-home beds or lack of availability of dialysis facilities. Callahan has merely brought rationing to the attention of a wider audience and has provoked much discussion as to how it should be applied. There is little doubt that in future rationing will have to be explicit, with widespread discussion and debate in a democratic fashion. The community to which it will be applied will have to be prime movers so that the self-imposition of such rationing is acceptable. Alternative proposals should not be discounted out of hand since much current policy has not been subjected to the same scrutiny. Flexible categorical rationing which has been the subject of public debate may be a good compromise, setting priorities clearly but allowing for discretion by the physician in individual cases. However, more fixed targets may be required if budgetary constraints are to be met reliably.

Dr Hackler has edited a fascinating collection of opinions from leading ethicists, philosophers and physicians. Their concerns for the future of the American health care system can be extrapolated to all societies, since the aging population and the provision of health care to increasing numbers of elderly patients is a worry for all concerned. This book is thoughtprovoking and whilst not reaching a consensus opinion, aims to providem several possible alternative strategies to deal with this daunting problem forên all providers of health care.

$$
\begin{array}{r}
\text { JO PORTER } \\
\text { Senior Registrar, } \\
\text { Department of Clinical Geratology, } \\
\text { Radcliffe Infirmary, } \\
\text { Oxford } \\
\text { Ox }
\end{array}
$$

\section{The Ethics of Human Gene Therapy}

\author{
Le Roy Walters and Julie Gage \\ Palmer, Oxford, Oxford University \\ Press, 1997, 209 pages, $\$ 25.95$.
}

Such is the pace of development in genetic research that books on the subject become outdated almost before they are timely. It is for this reason that Walters and Palmer's book has been ten years in the writing.

The authors have endeavoured to 3 strike a balance between giving readers the details of what is currently (orimminently) available, and raisigge some of the ethical challenges firs poses. It is a short book on a vast to gic and is obviously written with a viewroo attracting a wide readership. It is unlikely to be of interest to specialistso either in the field of human genetics oro in medical ethics. Where it may be of benefit is as a primer, either at under $\vec{\overrightarrow{ }}$ graduate level, or else for use with trainee health care professionals, within the context of a broader introduction to medical ethics. The authors clearly have one eye on the popular science market but as the book is presently only available in hardback, and given its brevity in relation to its price, it would require significant revision to achieve mass appeal.

They begin with the true story of the life and death of David, "the boy? in the bubble", afflicted with severe combined immune deficiencyos (SCID). Although this represents an laudable attempt to personalise oิ debate often dominated by technicali- $\omega$ ties, the account teeters dangerously close to Dickensian sentimentalityo This is compounded by the fact thato there is little done to relate this section? to the later chapters. The authors' 0 stated intention here is to show "that the field of human gene therapy is important" (page xvi). However, it is unclear that anyone disputes this. Certainly nobody who chooses to read this book would. Moreover, the 
existence of disease is an argument only against those who would question the benefit of medical research per se. The ethical issues raised by human gene therapy, insofar as they are distinguishable from the broader discussion of medical ethics, surely cannot be addressed by an appeal to extant human suffering.

This is followed by a clear and concise introduction to the science of genetics and the therapeutic implications of current research. These sections could be read profitably by anyone not familiar with contemporary developments and the scientific background to them. They are well written, accompanied by clear illustrations and the technical vocabulary is kept to a minimum. The first chapter deals with background Mendelian and postMendelian theory. Subsequent chapters are structured on the basis of what the authors refer to as the "conceptual distinctions" (page xvii) between somatic and germ line gene therapy and "between the prevention, treatment, cure of a disease, on the one hand, and enhancement of human characteristics or capabilities, on the other (page xvii). The fact that the authors acknowledge this latter set of distinctions as problematic, yet at no point make any sustained effort to expand upon this, prevents the work from moving beyond the level of a "whistle stop tour" of the issue. The authors argue that there is little substantively new raised by somatic therapy and even germ line techniques, and thus any difficulties can be effectively dealt with on the basis of control by public and expert opinion and codes governing submission of patients, such as the US National Institute of Health (NIH), Recombinant DNA Advisory Committee's Points to Consider (appendix D: 171-85).

In chapter four, we enter the area of enhancement therapy. This is where the most significant ethical issues arise and it is here that the strengths and weaknesses of the authors' treatment become most apparent. What we are offered is a wide-angled view both of the practical possibilities and the concomitant problems. It is the avoidance of abstract speculation in favour of laying out the facts that characterises the book. Anyone reading it for an indepth discussion of either technological or ethical issues is likely to be disappointed.

Were the book to be used for teaching purposes it would need careful handling as there are points at which the authors' eagerness to address as much as possible leads to what can only be viewed as flaws in the argument. For instance, very little attention is given to what must be a central (if not the central) issue: the control and allocation of resources. While this is clearly not something unique to genetically based therapies, if we accept, with the authors, that this is a vitally important area of medicine, then some reassurances need to be given that any benefits will be divided in the most equitable manner. What attention they do pay to the topic is limited to the idea that it ought to be something decided by appropriate legislation and quasialgorithmic codes of practice within a laissez-faire framework, perhaps modified by social and political mores. Conversely, the authors do little to assuage genuine public concerns regarding potential misuses. The spectre of eugenics hangs heavy over the whole field and while we may concur with the writers' assertions that the immorality of previous programmes lay in the immorality of their perpetrators, it is surely little comfort to be told that the impatience of tyrants, combined with the strength of democratic institutions will protect us (page 86). Given the obvious attraction of genetic therapy, absolute control over its allocation would be a welcome addition to any despot's arsenal. Neither would it necessitate the overthrow of parliamentary democracy to foresee a situation in which unscrupulous employers pressurised their workers into undergoing genetic therapy to reduce their desire for sleep, something the authors tell us is well within the realms of possibility (pages 114-5).

Bearing all this in mind the book could, with appropriate supplementation, become a valuable addition to a teaching programme. It would require a substantially longer and more detailed work to begin addressing some of the more profound problems that recombinant DNA therapy raises. It is to be hoped that we do not have to wait a further ten years for its appearance.

RICHARD PAUL HAMILTON Department of Philosophy, The University of Manchester

\section{Complementary Medicine and the Law}

Julie Stone and Joan Mathews, Oxford, Oxford University Press, 1996, 306 pages, $£ 30.00$ hc, $£ 12.99 \mathrm{sc}$.
The rise of complementary medicine in the United Kingdom poses a range of ethical issues for legislators and for the existing bodies regulating medical practice and professions associated with medicine. Some of these issues are particularly sensitive, as in the case with "ethnic medicine", where cultural sensitivities are involved. Most of us would accept that the government has a right (indeed, a duty) to regulate the availability of substances sold as drugs, but does this right extend to the exercise of control over what may be used by the practitioners of Chinese medicine who use substances which fall outside the range of conventional medicines? Some of these imported substances are adulterated with dangerous additions and are capable of harming the patients. Yet to regulate their use may be seen as insensitive to a claimed right of minority communities to pursue their own therapies in their own manner.

The authors of this exceptionally useful survey of the legal position of complementary medicine tackle this and related issues with tact. They are sensitive to the fundamental dilemma facing those who would subject complementary medicine to more rigorous control: such control, even if necessary to avoid the causing of harm by untrained and possibly unscrupulous practitioners, risks placing the complementary therapies in a straitjacket. The whole point of complementary medicine is that it pursues its goals in a way which differs from conventional medicine. Its resources, too, may be idiosyncratic; it may be difficult to prove the efficacy of a herbal remedy in the same way in which one may prove the efficacy of a Western drug. Clinical trials may not make sense in a system in which the practitioner is using a substance as part of the holistic treating of a patient. And then, of course, some remedies may defy the mechanistic notions of contemporary science. Can homoeopathic remedies possibly work in their extraordinary dilutions? Conventional science would answer that this is impossible, and yet homoeopathic practitioners point to the results they achieve as an indication that something is happening which conventional science may not be able to explain. For many believers in complementary therapies, the arguments used against them make sense only within a system of scientific explanation which they question. They resent 